NASA Technical Memorandum 105727

AIAA-92-3785

P.2S

\title{
An Overview of In-Flight Plume Diagnostics for Rocket Engines
}

G.C. Madzsar

Lewis Research Center

Cleveland, Ohio

R.L. Bickford

Aerojet Propulsion Division

Sacramento, California

and

D.B. Duncan

Duncan Technologies

Auburn, California

Prepared for the

28th Joint Propulsion Conference and Exhibit

cosponsored by the AIAA, SAE, ASME, and ASEE

Nashville, Tennessee, July 6-8, 1992 
$-15-5$

• 
An Overview of In-Flight Plume Diagnostics for Rocket Engines

\author{
G. C. Madzsar \\ National Aeronautics and Space Administration \\ Lewis Research Center \\ Cleveland, $\mathrm{OH} 44135$ \\ R. L. Bickford \\ Aerojet Propulsion Division \\ Sacramento, CA \\ D. B. Duncan \\ Duncan Technologies \\ Auburn, CA
}

\begin{abstract}
This paper presents an overview and progress report of the work performed or sponsored by the NASA Lewis Research Center (LeRC) toward the development of in-flight plume spectroscopy technology for health and performance monitoring of liquid propellant rocket engines. The primary objective of this effort is to develop technology that can be utilized on any flight engine. This technology will be validated by a hardware demonstration of a system capable of being retrofitted onto the Space Shuttle Main Engines for spectroscopic measurements during flight. The philosophy on system definition and status on the development of instrumentation, optics, and signal processing with respect to implementation on a flight engine are discussed in this paper.
\end{abstract}

\title{
INTRODUCTION
}

As rocket engine components experience wear or failure, anomalous materials may be entrained in the plume. Historically, visible plume anomalies have preceded many rocket engine failures ${ }^{-4}$. These plume anomalies typically are the result of eroded material passing through the engine and burning along with the propellants in the combustion chamber. Plume spectroscopy is the implementation of optical spectroscopic techniques for the analys is of the exhaust plume, utilizing the emission and/or absorption of spectral radiation by the exhaust gases as a means to determine its content. From the identification and quantification of plume content, an assessment of engine health and performance can be made.

The approach for this effort is to develop and demonstrate relevant spectroscopic technology on the Space Shuttle Main Engine (SSME). Specific devices developed include the nozzle mounted optic assembly (NMOA), and the Fabry-Perot interferometer (FPI) spectrometer. The NMOA, which is mounted to the aft manifold of the engine nozzle, collects spectral radiation from within the nozzle, throat, and combustion chamber of the engine; the FPI spectrometer selectively filters this plume radiation and measures the intensity at wavelengths that are characteristic of the eroding materials. These devices, currently being fabricated under contracts NAS3-25883 and NAS3-25624, respectively, are scheduled for testing on the Technology Test Bed Engine 
(TTBE) at MSFC. References 5, 6 and 7 describe the devices in detail. Figure 1 schematically shows the optic assembly and spectrometer in relation to the engine. In addition to the spectroscopic hardware, signal processing techniques for the extraction, identification, and quantification of spectral emissions, identification and quantification of alloy erosion, and the determination of the propellant mixture ratio are also being developed. Reference 8 discusses filtering techniques, while references 9 and 10 discuss alloy identification techniques. Although the specific hardware and software developed under the this program are intended for implementation on the SSME, the technology is generic, and could be incorporated into other rocket engines such as the space transportation main engine (STME), the advanced expander test bed engine (AETB) and other liquid or possibly solid propellant rocket engines.

Capabilities of a flight compatible plume spectroscopy system will include real time measurement and analysis of material erosion for engine safety monitoring, determination of performance parameters for feedback into the engine controller, and recording high-resolution, high-speed spectral data for post firing analysis of the engine.

\section{BACKGROUND}

Analysis of the exhaust from a combustion engine reveals the composition and thermodynamic state(s) of the gases. Engine health can be inferred from knowledge of gas composition, while engine performance can be inferred from knowledge of the gas state. Emission spectroscopy for rocket engine exhaust plumes is being investigated to determine if engine degradation can be established through detection of material erosion ${ }^{4}$. Knowledge of material erosion from internal components may provide insight into the engines' current health and remaining life.

Plume spectroscopy can be performed by using either emission or absorption techniques. Emission spectroscopy is based on measurement of spectral emissions from the thermally excited species in the plume, and absorption spectroscopy is based on absorption of spectral light by the species in the plume. From an instrumentation standpoint, emission spectroscopy is simpler than absorption spectroscopy since the number of optic components is minimized. In addition, a great deal of emission spectral data is available from ground test firings of the SSME. Therefore, this effort to develop a flight compatible system will initially examine application of emission spectroscopy to the SSME.

Figure 2 displays the propellant flow paths within the SSME. All particulates eroding from internal engine components within the flow paths are carried by the propellants into the combustion chamber where they are dissociated into atomic species, thermally excited, and emit their characteristic spectra as they exit the nozzle. By spectroscopically monitoring the plume, emissions from the various elemental species can be observed, enabling identification. Knowledge of which elemental species are in the plume enables identification of the eroding alloy and possibly the component from which the alloy eroded. Identification of the elemental species is relatively straightforward. Alloy and component identification is however, more complex since the SSME is fabricated from numerous alloys (many of which have common elemental 
constituents), and the appearance of various alloys in numerous components. Typically, plume spectroscopy can warn of impending failure from observation of sudden changes in the amounts of metals exiting the nozzle. Plume spectroscopy offers the ability to detect wear rather than the symptoms of wear.

Analysis of the plume from the SSME using emission spectroscopy is performed on a regular basis at MSFC and SSC during ground testing . The Optical Plume Anomaly Detection (OPAD) program sponsored by MSFC utilizes ground (test stand) based instrumentation. The high resolution emission spectra recorded from the TTBE by the OPAD instrumentation will be used as the reference for the NMOA/FPI instrumentation.

Figure 3 displays a time slice of the spectral history from TTBE firing 024 as recorded by the OPAD instrumentation. This time slice illustrates an example of failure detection utilizing plume spectroscopy. In this figure, emissions from $\mathrm{OH}$, background, and elemental species can readily be seen. $\mathrm{OH}$ emissions and background chemiluminescence are always observed in the SSME plume (with reasonably constant and consistent intensities), however emissions from metallic species typically vary with respect to the amount of material erosion that the engine is experiencing. Note that intensity of the $\mathrm{OH}$ and background chemiluminescence in Fig. 3 remain constant over time, but the intensities of the metallic lines (Specifically the labeled chromium line) varies with time. Analys is of the TTBE after firing 024 revealed that the faceplate of the engine had eroded. This faceplate is fabricated from Inconel 625, which contains chromium as an alloy constituent.

\section{PHENOMENOLOGY}

Radiance from atomic line emissions is a function of several variables. For plume spectroscopy, emission intensity is proportional to the total number density of the emitting species. It is assumed that the collection of atoms in the emitting system are in thermal equilibrium, and that there is a low population density of the emitting atoms. The intensity of an atomic line is given by the equation:

$$
I=\frac{A_{i j} N h(\nu) g_{i} e^{-E i / k T}}{Z(t)} \quad \text { eqn } 1
$$

Where $I$ is the emission intensity, $A_{i j}$ is the Einstein transition probability for spontaneou's emission, $N$ is the number density, $h$ is Planck's constant, $\nu$ is the frequency, $g_{j}$ is the statistical weight for each sublevel in the energy state $E_{i}, k$ is the Boltzmann constant, $T$ is the absolute temperature, and $Z(t)$ is the partition function.

In the rocket engine plume environment, low concentrations of free electrons are available for electron impact excitation of metal atoms. Virtually the entire population of atoms and molecules in excited states occurs through collisional impact between the molecules and the atoms ${ }^{11}$. Thus the excitation of metal species depends on the distribution of translational energy (temperature). 
The SSME combustion chamber operates at 205 atmospheres during 109\% power conditions with an oxidizer to fuel ratio of $6: 1$. Stagnation temperature in the combustion chamber is approximately $3300 \mathrm{~K}$, and $3200 \mathrm{~K}$ in the Mach disc at the nozzle exit. The engine is overexpanded at sea level and underexpanded in the vacuum of space. A discussion regarding SSME plume characteristics can be found in reference 14. The radiant power and line widths of spectral emissions emanating from metallic species that may appear in the combustion chamber were calculated ${ }^{5,6}$ based on chamber temperature, chamber pressure, propellant flow rates, and the flowfield properties. The flowfield properties were calculated using the One Dimensional Equilibrium (ODE) ${ }^{12}$ and the Two Dimensional Kinetics (TDK) ${ }^{13}$ computer codes.

During engine start, the SSME nozzle undergoes significant mechanical distortion and is subjected to thermal shock. Video tape observations place distortion of the major diameter at approximately 6 inches, and analysis indicates that the aft manifold of the nozzle experiences a $7500-g$ shock during start up. From TOK code analyses, the convective heat flux was calculated to be $2.7 \mathrm{MW} / \mathrm{m}^{2}$.

\section{INSTRUMENTATION REQUIREMENTS}

Developing a set of requirements for flight compatible plume spectroscopy instrumentation was accomplished by evaluating the spectral characteristics of the plume flowfield, and determining which elemental species must be monitored to enable detection of erosion in critical engine components. Consideration was given to constraints imposed on the instrumentation by the engine environment, constraints imposed by the high speed nature of the phenomena being observed, and recognition that the size and weight constraints are critical for flight compatible systems.

Spectral characteristics considered were the relative intensities and wavelengths of the atomic, molecular and continuum emissions. Environmental considerations included the temperature excursions, thermal shock, and vibration caused by engine operation. Flight consideration consisted of optimizing the view and collection of the emissions with respect to the location of greatest spectral intensity within the plume during flight, determining how and where the instruments can be mounted on the engine/vehicle, and minimizing instrumentation size and weight.

Plume spectroscopy instrumentation typically consists of an optical device to collect spectral radiation from the exhaust, an optical fiber to transfer this radiation to a spectrometer, and a spectrometer to separate the radiation into its characteristic spectrum from which plume analysis can be performed. The primary consideration for an optic collection device with respect to spectral measurements is its view of the plume. The combustion chamber, throat plane, and mach discs are areas of strong spectral emissions and therefore the logical sources for spectral emission measurements.

A spectrometer separates the plume emissions into its characteristic wavelengths, from which identification of the exhaust constituents can be made. The primary considerations for flight type spectrometers are its wavelength range, resolution, sensitivity, dynamic range, size, weight, and ruggedness. The bandwidth of 'interesting' spectral phenomena from the SSME 
extends from approximately 280-1000 nanometers $(\mathrm{nm})$. Atomic emissions from the metallic species typically occur between 300 and $500 \mathrm{~nm}$, emissions from the $\mathrm{OH}$ radicals typically occur between 280 and $320 \mathrm{~nm}$, and emissions from $\mathrm{H}_{2} \mathrm{O}$ occur between 700-1000 nm. As will be discussed later, the actual band width for monitoring the SSME is 320 to $430 \mathrm{~nm}$, and resolution must be at least 0.05 $\mathrm{nm}$.

Signal processing is required to extract the atomic lines and identify the alloy/component from line information. The line radiation must be extracted from the overall radiation at a given wavelength. The overall radiation is the sum of emissions from the various atomic sources, molecular sources, and background chemiluminescence. In addition the spectral acquisition, extraction, and identification process must occur quickly if action is to be taken based on spectral phenomena. Therefore signal processing considerations consists of optimizing the data acquisition and analysis rates.

\section{TECHNOLOGY DEMONSTRATION}

The plume spectroscopic hardware that is being fabricated and tested to evaluate flight compatible plume spectroscopic technology consists of the NMOA, the FPI spectrometer, and a computerized signal processing system. These devices are being developed to meet the measurement and instrumentation requirements described above. Following is a discussion regarding application of this technology to the SSME. Although some of the hardware is specific to the SSME, the logic utilized to select and develop the technology is generic, and is applicable to any chemical rocket engine.

\section{Emission Source}

The ideal source of radiation for plume spectroscopic measurements during flight is from within the nozzle of the engine. All eroding particulates from internal engine components pass through the nozzle, enabling an accurate measure of particulate erosion. Viewing towards the throat eliminates the need for subtracting the solar background. Calculations have shown that radiation from the combustion chamber is orders of magnitude greater in intensity than radiation from the mach disc, allowing for measurement of lower level signals while increasing the signal to noise ratio. Analyses has shown that optics can be fabricated to survive the environment at the nozzle lip ${ }^{3}$. Structural failure of a nozzle mounted optic device will not cause damage to the engine since any fragmented parts will fall below the engine.

To monitor plume emissions, the optics can be (1) mounted off the engine (vehicle) and view the mach disc, (2) mounted on the nozzle of the engine to view the mach disc, (3) mounted in the ignitor or injector to view the chamber/throat/mach disc areas, (4) mounted in the side of the combustion chamber/throat to view the chamber, or (5) mounted on the lip or in the side of nozzle to view up into the nozzle of the engine.

The mach disc is readily accessible and provides an adequate optical signal for plume spectroscopy. To view the mach disc, the optics may be mounted away from the engine, eliminating the need for environmentally rugged optics. The OPAD program is based on mach disc observations using hardware mounted to the test stand. Although the mach discs are readily accessible, they are not the 
ideal source for plume measurements on a flight system since radiation from a source behind the discs (such as the sun) may enter the collection optics along with the plume emissions, requiring that this potentially varying background be known to enable its removal from the measured radiation. 0ther difficulties with optics focused on the mach disc during flight include movement of the discs with respect to the nozzle (since disc location is a function of back/atmospheric pressure), the disappearance of the mach discs in the vacuum of space, and that not all gases (and therefore not all particulates) pass through the mach discs. Therefore, a plume diagnostic system utilizing the mach disc of an ascending rocket as the optical source is usable until the vehicle leaves the atmosphere, must be capable of separating and subtracting the solar background from the plume emissions, and must have optics that are movable and focusable to enable tracking and imaging the mach disc.

With the collection optics mounted in the ignitor or injector of the engine, view of the chamber, throat, and mach disc are possible. Difficulties with this location for the optics include the need for background subtraction, and the concern with structural integrity. Background subtraction is required since the optic view extends out through the nozzle, allowing background light to be collecting along with the plume emissions. The second consideration is structural. The optics must withstand the severe temperature, thermal shock, and pressure of the combustion chamber. If the optics fail structurally, an exit path for the combustion gases other than through the nozzle may result, leading toward reduced performance or possibly catastrophic failure of the engine. While mounting the optics in the side of the combustion chamber facing toward the injectors eliminates the need for background subtraction, the structural issues remain unresolved.

\section{Spectrometer Selection}

An interferometer based spectrometer was selected for this application based on its small size, high-resolution, and high-speed spectral acquisition capabilities. A Fabry-Perot interferometer was selected based on its spectral bandwidth, simplicity of design, and commercial availability. Engineering an appropriate housing for the interferometer resulted in a rugged, compact, lightweight spectrometer. It is anticipated that on a vehicle such as the space shuttle, the spectrometer will be mounted to the engine bulkhead.

Four types of wavelength separating devices may be used as spectrometers for observing plume spectral phenomena. Interference filters, prisms, diffraction gratings, and other interferometric devices can selectively observe specific wavelengths containing the spectral phenomena of interest. For plume spectroscopy, interference filters alone are not a good choice since their high bandpass (1-5 nm), results in inadequate resolution of the atomic lines. To meet the resolution requirement, grating/prism type spectrometers typically have a long optical path length. Grating/prism devices are sensitive to vibration, temperature variations, and contamination. They are relatively heavy (for rigidity), and physically large (for the long path length). This type of spectrometer is designed for use in the laboratory and not readily adaptable for flight instrumentation. 
Specie Selection

The selection of the number and identity of the species to be monitored is based on the requirement to monitor all critical engine components.

Evaluation of the alloy/element content of the various components in the propellant flow paths will reveal a minimum number of species that must be monitored. Following is a discussion regarding the specie selection process for the SSME.

Alloys from which the SSME is fabricated are listed in Table 1. This table lists the alloys, their elemental constituents, and the weight fraction of these elemental constituents ${ }^{14}$. Table 2 is a list of the SSME components in the propellant flow path and the alloy from which they are fabricated. Note that any impurities that may be in alloys/propellants are not included in the above tables. From Table 1 it can be seen that one or more of the elements chromium, cobalt, iron, nickel, manganese, and tungsten are constituents in each SSME alloy. In addition, copper and calcium are elemental constituent of critical SSME components. Therefore, monitoring for these 8 species enables detection of erosion from all SSME alloys and critical components.

Chromium is clearly an important candidate for plume monitoring based on its use as a major alloy constituent in most superalloys and steels. Erosion of the LOX posts and/or injector, failure of the HPOTP and HPFTP turbine blades, disks, and bearings, and other failure modes have a high probability of producing the chromium spectrum in the plume. As will be seen, chromium is one of the most sensitive indicators of alloy erosion. Cobalt, iron and nickel are the primary ingredients in the majority of the structural alloys used in the SSME hot gas components. Manganese and tungsten are constituents of some SSME alloys; detection of these elements enables alloy identification.

Within the SSME, copper is a major constituent of NARToy A, NARToy $Z$, and KMonel. NARloy $Z$ is found in the main combustion chamber, NARLoy $A$ is used in the preburner baffles, and K-Monel is used in the low pressure oxidizer turbopump (LPOTP) inducer, inlet liner, rotor, and stator. Historically, copper has been seen in the plume during erosion of the main combustion chamber and baffles.

Calcium is an important specie to monitor for detecting bearing and cage degradation in the high pressure oxidizer and fuel turbopumps (HPOTP \& HPFTP). The calcium content of the Armalon bearing cage material is approximately $6 \%$, and has been seen in the plume during bearing degradation.

\section{Specie Detection}

From the calculated radiant power values of the 8 elemental species (in the combustion chamber) and the sensitivity of the photomultiplier detectors used in the spectrometer, the minimal detection limits (MDL) in parts per million and grams per second for the 8 species were derived ${ }^{5,6}$. Table 3 lists the species, the wavelength of the emissions, atomic linewidths at the chamber pressure, and the optical fluxes arriving at the NMOA for each atomic species at MDL concentrations. From these MDL's of the individual species, the alloy loss rate based on observation of the individual species at the MOL was calcuiated and is listed in Table 4. 
From Table 3 it can be seen that the wavelengths for the 8 species to be monitored are between 320 and $430 \mathrm{~nm}$, dictating the required bandwidth of the spectrometer. Resolution of the spectrometer must be sufficient to resolve closely spaced spectral lines; including the pressure broadening effects. From Table 3 it can be seen that narrowest spectral line is $0.2 \mathrm{~nm}$ wide. Nyquist sampling theory dictates that as a minimum, two points must be measured (corresponding to the peak and adjacent valley) in that $0.2 \mathrm{~nm}$ line to enable a measurement. Typically, more than two points are used to insure proper resolution, therefore four points will be used, corresponding to a spectrometer wavelength resolution of $0.05 \mathrm{~nm}$. This resolution is required to resolve narrow spectral lines as well as resolve closely spaced lines.

Nozzle Mounted Optic Assembly

The NMOA that is currently being tested on the TTBE is shown in Figure 4 . This device is bolted to the lip of the nozzle, and collects radiation from the throat and combustion chamber. The radiation is focused into an optical fiber, which transmits the light to the spectrometer.

A lens/turning optic is required to focus and direct the spectral radiation. The lens defines the field of view for radiation collection, and the turning optic directs the radiation into the optical fiber. The turning optic is required since the radius of curvature of the aft manifold exceeds the allowable bend radius for fiberoptic bundles. To simplify the optical design and minimize optical losses, the f-number matching lens and turning optic are integrated into a single element. A metallized coating is used on a 45 degree surface to turn the optical path shown in Fig. 4.

A fused silica fiberoptic bundle with a modified SMA connector transfers light from the NMOA to the spectrometer. The removable fiberoptic cable allows for simple installation and removal of the NMOA and FPI spectrometer. A metal band at the fiber bundle termination prevents relative motion between the fibers, and provides reference surfaces for accurate termination alignment.

Spectral emissions collected by the NMOA originate from within the combustion chamber. The field of view for the optic is therefore set by the throat area. The field of view of the throat from the nozzle lip is 4.1 degrees. A fused silica optical fiber has a numerical aperture of approximately 0.28 in the UV, which is equivalent to roughly 30 degrees acceptance angle. Therefore, a lens is utilized to match the viewing angle with the fiberoptic acceptance angle. Using a $2.5 \mathrm{~mm}$ lens, the throat image spot size is $0.4 \mathrm{~mm}$. When focused on a $0.8 \mathrm{~mm}$ diameter bundle, a field of view twice the throat area is provided. This enables observation of the throat during all aspects of engine firing; including the time when the engine nozzle is distorted during the start transient.

The NMOA is engineered to withstand the nozzle environment, and is a simple installation/retrofit onto the existing SSME nozzle. The device is bolted to the nozzle aft manifold through existing threaded holes. The design of the NMOA is a compromise between weight, size and strength. It is fabricated from precipitation hardened zirconium-copper with a zirconium oxide thermal barrier coating applied to the chamber exposed end. Finite element analysis indicates that the NMOA will withstand the thermal and mechanical stresses during the start up, steady state, and shutdown without yielding. Conduction cooling 
from the NMOA into the aft manifold is used to cool the device since cryogenic hydrogen circulates through the aft manifold. Preliminary testing on the TTBE verified the structural integrity of the NMOA during engine operation. The probe weighs approximately 2 lbs.

At this time, it is unclear as to where the optimum location for collection of spectral emissions within the nozzle/throat/chamber is. Initial thoughts were that the ideal location is from within the combustion chamber. As will be discussed later in this paper, line emissions were not seen emanating from the chamber. Currently, alternate view locations are being investigated.

Fabry-Perot Interferometric (FPI) Spectrometer

The Fabry-Perot interferometer has sufficient bandwidth and resolution for use on a plume diagnostic system. These devices can be extremely small, compact and lightweight. A spectrometer based on a Fabry-Perot interferometer using photomultiplier tube (PMT) detectors has the required sensitivity and dynamic range for application to plume spectroscopy. Technical description of a Fabry-Perot interferometer can be found in reference 15 .

An FPI is a tunable narrow band filter (tunable etalon), which produces a periodic set of transmission peaks (orders) corresponding to wavelengths that are integer multiples of the mirror spacing. For spectroscopic purposes, the radiation passing through the FPI requires additional filtering to reduce the number of orders transmitted to the detectors. Dielectric narrow bandpass interference filters are used for this order sorting. Figure 5 shows a typical filtering scheme for the FPI spectrometer. The interferometer allows radiation at a finite number of wavelengths to pass through (seen as the transmission peaks). The wavelength of one of the transmission peaks corresponds to the emission wavelength of a specie of interest. Exiting the interferometer, radiation at the 'unwanted' wavelengths are eliminated by a bandpass filter. The tunable interferometer in combination with the fixed bandpass filter yields a high resolution spectrometer.

The FPI spectrometer that is currently being fabricated is shown schematically in Fig. 6. Spectral radiation enters from the optical fiber and passes through a lens where it is collimated. The collimated light then proceeds through a beam splitter, which discards the IR and UV radiation that is not of interest. The beam splitter also enable introduction of spectral radiation from a hollow cathode lamp (HCL) into the device for calibration purposes. The radiation then passes through the tunable etalon. The etalon mirror spacing is controlled by piezoelectric drivers. Exiting the etalon, the light enters an order sorting filter/prism/beam splitter, that splits off the 'order' containing the wavelength of interest (by means of interference filters coated onto the prism surface) and directs the spectral radiation into a photomultiplier tube. In essence, the interference filters place a $1 \mathrm{~nm}$. wide 'window' around the wavelength corresponding to specie emission, and the tunable etalon steps through that window in $0.05 \mathrm{~nm}$ increments.

The etalon mirror gap controls the spacing between transmission maximums. For broadband input, smaller gaps increase the transmission peak spacing and larger gaps decrease it. The mirror spacing controls how many orders lie within the bandpass filter transmission bandwidth. An interferometer free spectral range (FSR) that is less than the filter bandwidth allows 
transmission from more than one order which is detrimental when monitoring for an atomic specie emission. Operating with a FSR larger than the filter bandwidth results in excessive FPI bandwidth, thereby increasing the background transmission. Background is minimized by selecting a FSR approximately equal to the filter bandwidth, as is illustrated in Fig. 5 .

Finesse, which is the ratio of the transmission bandwidth to the spacing between orders (FSR), determines the FPI background transmittance at resonance. Increasing finesse decreases the transmission bandwidth with a fixed mirror gap. Off resonance transmission contributes to background signal.

The FPI transmits wavelengths of light that are multiples of the distance between the mirrors. A dielectric coating was placed on the mirrors allowing operation from 320 to $430 \mathrm{~nm}$, with a reflectivity of approximately $93 \%$. Outside of the operating range, transmission through the FPI falls off substantially, effectively blocking unwanted radiation. UV radiation from the $\mathrm{OH}$ emissions, and IR radiation from the $\mathrm{H}_{2} \mathrm{O}$ molecules is be blocked. Blockage of unwanted radiation helps ensure a high signal to noise ratio.

The photomultiplier tubes selected for the TTBE FPI have detection thresholds of $10^{-12}$ watts. Testing has shown that optical losses in the system will attenuate the incoming signal by a factor of 100 . From these values, it has been determined that a spectrometer entrance aperture greater than $0.2 \mathrm{~mm}$ diameter will provide an optical signal that exceeds the photomultiplier detection limit at the SSME MDL, considering losses.

\section{Signal Processing}

The complete spectrometer system consists of the FPI spectrometer, the $\mathrm{HCL}$, an associated processor module for control, data acquisition, data storage, and processor electronics. The FPI software consists of pre-test processing, run time processing, post test processing, and I0 interface routines. Pre test processing performs the initialization and set up of the system. This includes self calibration (using the $\mathrm{HCL}$ ) and self test of the data acquisition/processing electronics to insure its proper operation. During engine firing, the run time processing routine will generate the FPI SCan waveform for the piezoelectric drivers, perform the background subtraction of the species, and check spectral intensity against specie redlines. Data acquisition, background subtraction, and redline check occurs simultaneously for the 8 channels every 10 milliseconds. At the conclusion of the engine firing the post test processing routines will calculate and check spectrometer finesse, and replay stored spectral data. Human interaction with the system will be through a graphical user interface that enables input of user defined configurations, and values for specie redlines.

In order to determine the absolute intensity of the atomic emissions, the chemiluminescence, or background, onto which the atomic lines are superpositioned must be subtracted. The FPI spectrometer has an active background subtraction capability. As the intensity is measured at $0.05 \mathrm{~nm}$ increments in the $1 \mathrm{~nm}$ window around each spectral line, sample and hold circuitry is used to measure the minimum and maximum values. The maximum intensity value corresponds to the spectral line peak, and the minimum intensity value (intensities measured on either 'side' of the spectral line) 
corresponds to the background. Subtraction of the minimum from the maximum reveals the absolute intensity of the spectral line.

The entire system is controlled by a commercially available 386 based computer. The computer has a 2 channel 12-bit digital to analog converter (DAC), a 16 channel 12-bit analog to digital converter (ADC), 8 digital input/output (I/0) lines, 16-bit direct memory access (DMA), a 1.2 Gb hard disc, and a $150 \mathrm{Mb}$ magnetic tape drive. The DAC generates the analog ramp waveform to drive the piezoelectric drivers, and the ADC's digitize the spectral intensities from the FPI. The $1 / 0$ lines are the output from the system to enable control action in the event that a redline has been

encountered. The hard disc is used for data storage during engine firing, and the DMA enables high speed writing to the disc. The magnetic tape unit is used for archive purposes.

The logic used to for data acquisition and control is shown in Figure 7 . The logic has been implemented through the commercially available "LABVIEW" software package. Upon initiation and login procedures, a logic branch is encountered. One branch enables system calibration, and the other enables spectral acquisition/processing during engine firing. Selection of the calibration branch activates the HCL and varies the power supply outputs until the appropriate settings for the 8 PMT's are reached. These calibration points are written to a file.

Selection of the operation branch in the data acquisition and control scheme enables spectrometer operation during engine firing. At this point, the system is armed and waits the engine fire signal (FS1 on Fig. 7). Upon engine ignition, the system: (1) controls the FPI ramp generator, (2) records the PMT signals, and (3) calculate (and store) the spectral intensity and background level for each channel. The spectral intensities for the 8 channels are checked against preset redlines, and an appropriate signal is placed on an $1 / 0$ line if a redline is exceeded. Upon receiving the engine off signal (FS2 on Fig. 7), all data files are closed, and the system is recycled. The recycle enables system shutdown, a calibration check, or reset of the system for another engine firing.

\section{STATUS}

A breadboard FPI spectrometer has been fabricated and tested. This 3 channel unit $(324.7 \mathrm{~nm}, 377.6 \mathrm{~nm}, 425.4 \mathrm{~nm}$ ) was tested using a seeded flame (copper and chromium) as the optic "source". Figure 8 displays the 3 channel unit and the testing apparatus. The copper 1 ine at $324 \mathrm{~nm}$ and the chromium line at 424 $\mathrm{nm}$ were selected for this unit since they have been identifies as two of the species required for SSME monitoring, and the wavelengths are at the extremes of the bandwidth. The thallium line at $377.6 \mathrm{~nm}$ was included in this unit since it does not appear in the SSME and could therefore be used as wavelength reference.

The intent of the 3 channel unit was to: (1) validate the concept, (2) validate the design approach, and (3) evaluate the performance of FPI based spectrometers. Testing was performed to evaluate the optical sensitivity of the unit, and evaluate the effects of vibration, static acceleration, temperature variations, and background radiation on the overall performance. 
Using the seeded burner rig as the optical source, it was found that the measured signals recorded during the tests agreed with the calculated signal strength, thereby verifying the predicted sensitivity of the unit.

Vibrational testing was performed by observing the detector output while subjecting the FPI spectrometer to random impacts of varying amplitudes. Minimal changes were observed during the impacts. Static acceleration tests were performed by rotating the orientation of the spectrometer with respect to the earth and measuring the spectrometer's finesse at the various orientations. It was found that the finesse does vary with orientation, thereby indicating sensitivity to static acceleration. This sensitivity to acceleration was not great enough to warrant the modification and/or redesign of the spectrometer. To test for sensitivity to temperature variations, the finesse was measured during heating of the spectrometer with a heat gun. It was found that thermal induced drift does occur. This was not unexpected, since the interferometer itself has a long path length and large diameter (1 inch) optics. Smaller diameter optics and a shorter path length interferometer will minimize thermal effects. To test for sensitivity to background radiation, the cover of the spectrometer was removed to allow leakage of ambient light. It was found that the spectrometer can be extremely sensitive to light leakage.

It was concluded from the tests that the breadboard FPI spectrometer successfully validated the concept and the design approach. The optical performance matched the design predictions, and environmental testing indicated that flight compatible spectrometers are feasible. Based on the successful testing of the 3 channel unit, an 8 channel unit was designed using the same concepts. Differences between the 3 and 8 channel units include elimination of the reference specie, replacement of the silicon detectors with PMT's, and use of 0.25 inch optic elements instead of 1 inch optic elements. The smaller diameter optics reduced the overall size and weight of the spectrometer, increased its structural rigidity, and reduce its thermal sensitivity. It is not anticipated that the reduction in radiance throughput caused by the decrease in the size of the optics will drastically change the MDL values.

From the tests it was determined that a unique reference specie was not necessary. Instead, a $\mathrm{HCL}$ containing the 8 species $(\mathrm{Cr}, \mathrm{Co}, \mathrm{Fe}, \mathrm{Ni}, \mathrm{Mn}, \mathrm{Cu}$ and $\mathrm{Ca}$ ) will be used, resulting in an accurate wavelength reference and calibration point for all 8 species. PMT's will be used in place of silicon detectors for the 8 channel unit. The PMT's have greater sensitivity and dynamic range in the 300 to $500 \mathrm{~nm}$ bandwidth, and their responsivity falls off appreciably above $650 \mathrm{~nm}$; resulting in an increased measurable range of spectral intensities in the bandwidth of interest while decreasing the unit's sensitivity to $I R$ radiation (IR from the $\mathrm{H}_{2} \mathrm{O}$ in the plume).

The design of the 8 channel unit is complete. After the design review, fabrication was initiated. The unit is scheduled for testing on the TTBE in June of 1993.

A NMOA has been fabricated and tested on the TTBE. This version (Fig. 4) viewed the engine chamber/throat directly. Structurally, the NMOA survived the engine with no degradation. However, the recorded spectra does not appear to reveal atomic line structure (generally, line structure is seen in spectra measured from the Mach disc). The observed spectra (Fig. 9) appears similar 
to that of a black body radiation source with the intensity peak at approximately $520 \mathrm{~nm}$. Several mechanisms have been postulated to explain the spectral shape from these tests; among them blackbody radiation from high pressure gases, Rayleigh scattering off molecules within the chamber, and scattering off the chamber wall. Note that at the time of this writing, analysis of the spectrum is not complete and conclusive results are not available.

Additional test are planned with a modified NMOA. A new lens will be fabricated to change the field of view to just below the throat. The pressure in the nozzle drops off significantly below the engine throat. It is thought that observing the plume in a lower pressure regime may enable observation of spectral lines.

If further testing indicates that spectroscopy based on emissions from the engine chamber, throat or nozzle do not provide "usable" data, the emphasis of this program will shift to absorption spectroscopic techniques. A pair of NMOA's will be mounted diametrically across the nozzle, with an optic view across the exit plane of the nozzle. One of the NMOA's will emit spectral light (provided by a $\mathrm{HCL}$ ) of known intensity, and the other NMOA will collect the light that travels across the exit plane of the engine. The collected light will be measured and analyzed by the FPI spectrometer. The identity and quantity of the metallic species in the plume can be determined from the amount of light that is absorbed as it travels across the exit plane.

\section{SUMMARY}

The overall objective of this effort is to develop and demonstrate a flight compatible plume monitoring system for detecting degradation or failure of rocket engine components. A specific task is to develop and test flight compatible instrumentation to monitor emissions from metals entrained in the SSME flowfield. This instrumentation consists of a nozzle mounted optic assembly (NMOA), a Fabry-Perot interferometric (FPI) spectrometer, and a fiberoptic cable to transmit the collected spectral radiation from the NMOA to the FPI spectrometer. These devices are currently being fabricated, and scheduled for testing on the Technology Test Bed Engine (TTBE).

The nozzle mounted optic assembly collects radiation emitted from metallic species that have eroded from internal engine components and have been carried by the propellants into the engine chamber. The radiation is transferred from the NMOA to the FPI spectrometer via a fiberoptic cable. The NMOA will enable the monitoring of spectral emissions during space shuttle earth-to-orbit operations. No modifications are required to the SSME's. Analysis has shown that the optic will be capable of viewing the chamber, throat, and nozzle throughout the entire flight envelope. Testing and analys is has indicated that the device will withstand the thermal and mechanical loads imposed by engine operation. The optic assembly poses no risk to the engine based on analys is performed to date.

Initial testing of the NMOA on the TTBE reveals spectra that appears similar to a black body radiation source with the peak at approximately $520 \mathrm{~nm}$. No atomic specie line were discernable. At this time the mechanism describing this phenomena is unknown. A new lens will be fabricated for the NMOA to 
change the field of view to just below the throat. It is thought that observing the plume in a lower pressure regime may enable observation of spectral lines.

The Fabry-Perot interferometer based spectrometer is a rugged, lightweight, compact, high resolution spectrometer capable of detecting the spectral signatures of eroding engine components. The FPI based spectrometer is smaller and lighter than grating or prism devices, and will provide greater wavelength resolving capability. A 3 channel breadboard FPI spectrometer was fabricated and tested; demonstrating the resolution, sensitivity, signal to noise, and environmental insensitivity desired for flight compatible spectrometers. Within the limitations inherent in the breadboard design, the key features required to provide confidence in the FPI have been demonstrated.

The 8 channel unit that is currently being fabricated has real time digital processing capabilities $(10 \mathrm{~ms})$ with active background discrimination. The device will have a bandwidth of 320 to $430 \mathrm{~nm}$ and a resolution of $0.05 \mathrm{~nm}$. This unit will monitor eight spectral lines corresponding to eight distinct metallic species. These species include chromium, cobalt, iron, nickel, manganese, tungsten, calcium, and copper. It has been shown that these species will enable observation of bearing degradation and erosion of any alloy from components along the propellant flow paths.

\section{REFERENCES}

1. Cikanek, H.A., et al., "Space Shuttle Main Engine Plume Spectral Monitoring Preliminary Results", AIAA Paper No. 87-1792, July 1987.

2. McCoy, R.G., et al., "Analys is of UV-Visible Spectral Radiation from SSME Plume", 16th JANNAF Propulsion Conference, San Diego, CA, December 1987.

3. Powers, W.T. and Cikanek, H.A., "Analysis of UV-VIS Spectral Radiation from SSME Plume", Advanced Earth to Orbit Propulsion Technology 1988, Vol. 2, R.J. Richmond and S.T. Wu, eds., NASA CP-30120-VOL-2, 1988, pp. 595-611.

4. Powers, W.T., et al., "OPAD Through 1991 - Status Report \#2", 3rd Annual Health Monitoring Conference for Space Propulsion Systems, University of Cincinnati, 1991, pp 169-184.

5 . Bickford, R.L., Duncan, D.B., and Madzsar, G.C., "Development of a FabryPerot Interferometer for Rocket Engine Plume Monitoring", 2nd Annual Health Monitoring Conference for Space Propulsion Systems, University of Cincinnati, 1990, pp 160-168.

6. Bickford, R.L., and Madzsar, G.C., "Fabry-Perot Interferometer Development for Rocket Engine Plume Spectroscopy", AIAA paper 90-2234, July, 1990.

7. Bickford, R.L., Duncan, D.B., and Madzsar, G.C., "Space Shuttle Main Engine Nozzle Mounted Optic Assembly for Throat Plane Spectroscopy", AIAA paper 91-2524, June, 1991. 
8. Madzsar, G.C., "Digital Filtering of Plume Emission Spectra", AIAA Paper No. 90-1994, July, 1990.

9. Nail, B., and Wu, S.T., "A Signal Preprocessing Algorithm Applicable to Both the DTF and SSME Spectral Diagnostics", 3rd Annual Health Monitoring Conference for Space Propulsion Systems, University of Cincinnati, 1991, pp 203-215.

10. Madzsar, G.C., "Determination of Alloy Content From Plume Spectral Measurements", AIAA Paper No. 91-2531, June 1991.

11. Alkemede, C., Herrmann, R., Fundamentals of Analytic Flame Spectroscopy, John Wiley \& Sons, 1979.

12. Gordon, S., and McBride, B.J., "Computer Program for Calculation of Complex Chemical Equilibrium Compositions, Rocket Performance, Incident and Reflected Shock, and Chapman-Jouguet Detonations" NASA SP-273, Interim Revision, 1976.

13. Nickerson, G., et al., "The Two Dimensional Kinetic (TDK) Reference Computer Program", Engineering and Programming Manual, Software Engineering Associates, Inc., prepared for Contract NAS8-35931, NASA/MSFC, April, 1985.

14. Tejwani, G.D. and Gardner, D.G., Preliminary Report: "Engine Diagnostics Database Development and DTF Seeding Experiment Test Matrix", NASA-SSC Report No. TWR J9-A901, 14 July 1989.

15. Hernandez, G., Fabry-Perot Interferometers, Cambridge University Press, 1986. 


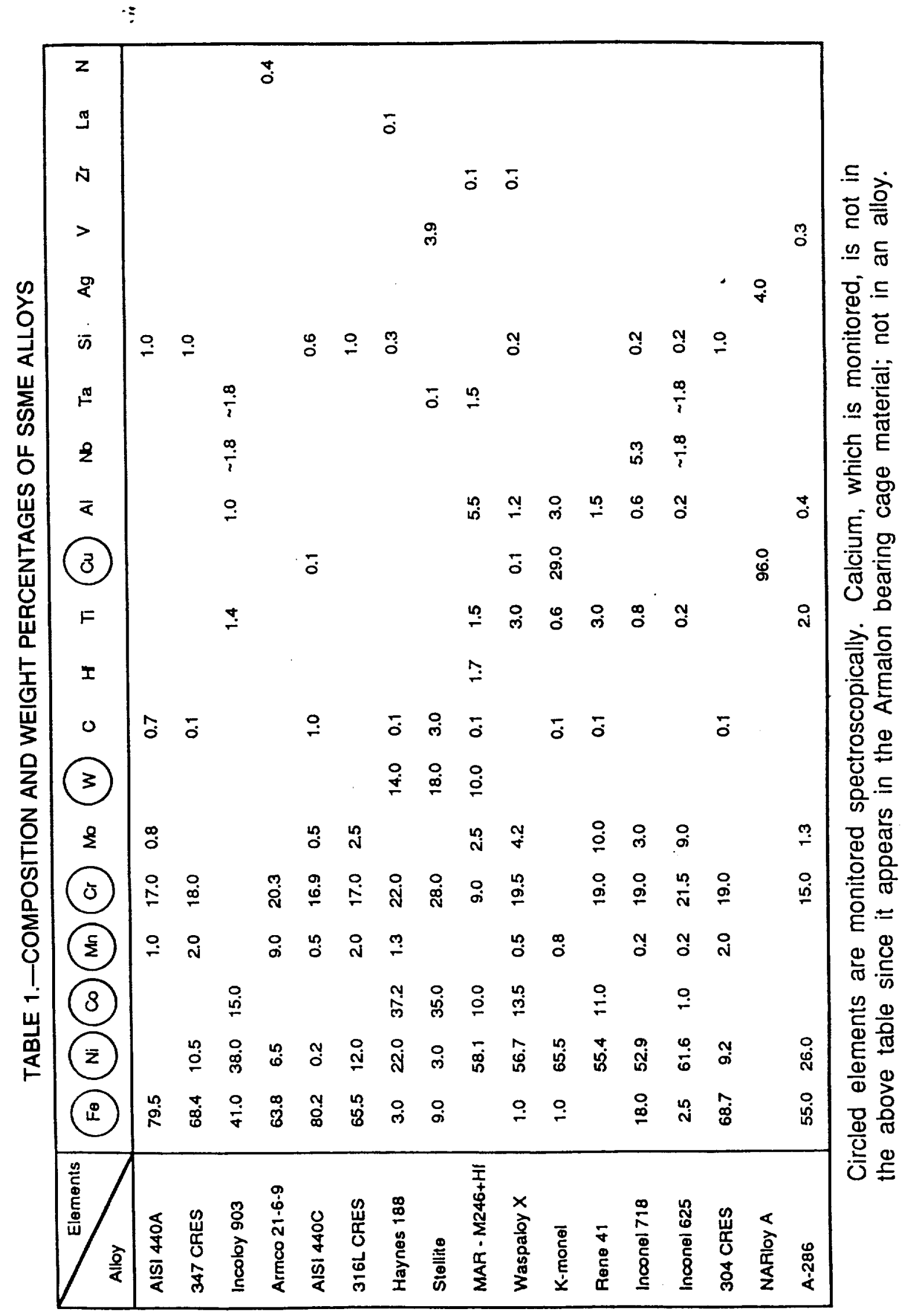




\section{TABLE 2.-SSME COMPONENTS AND MATERIALS}

(PARTIAL LIST)

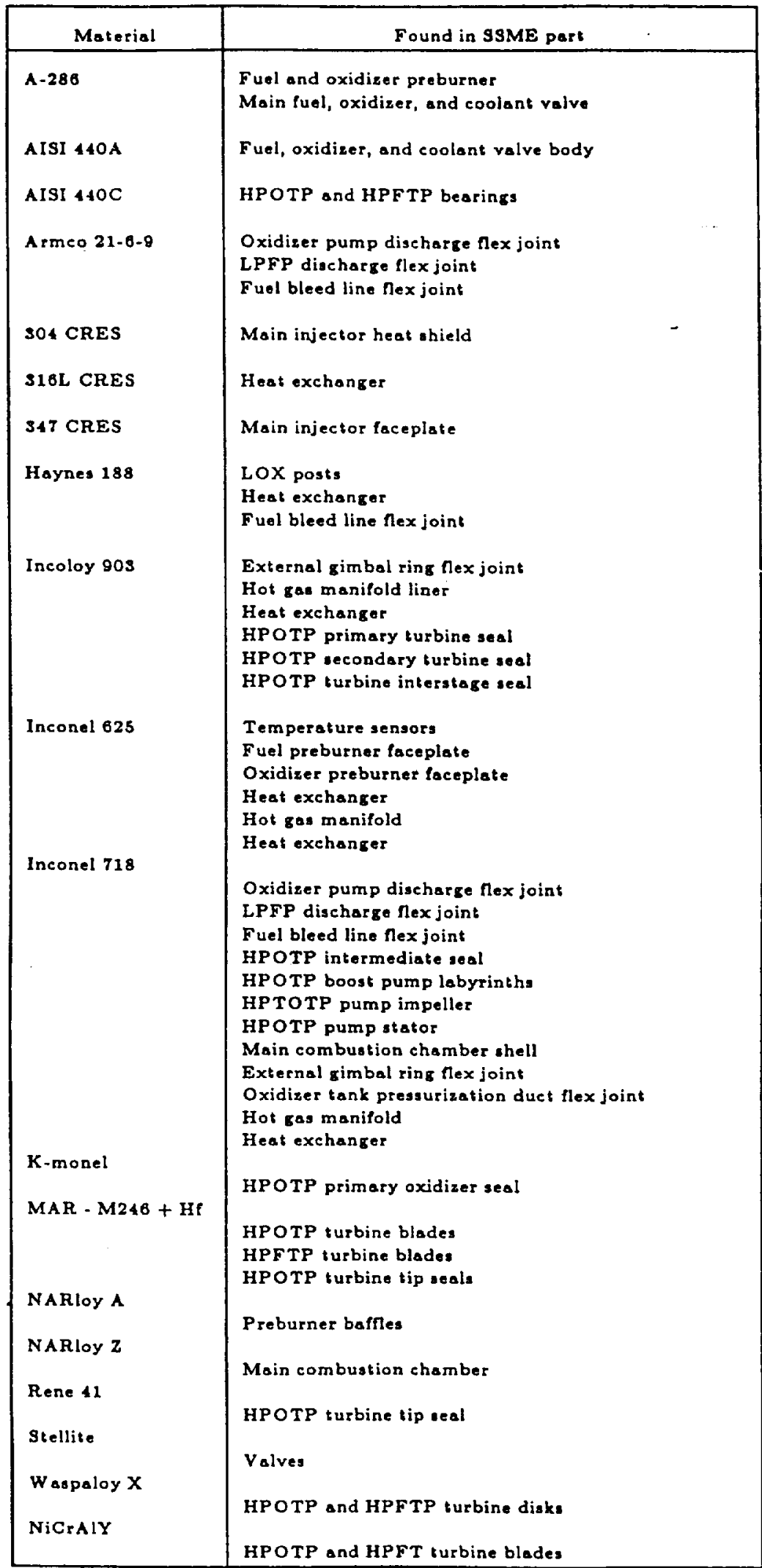




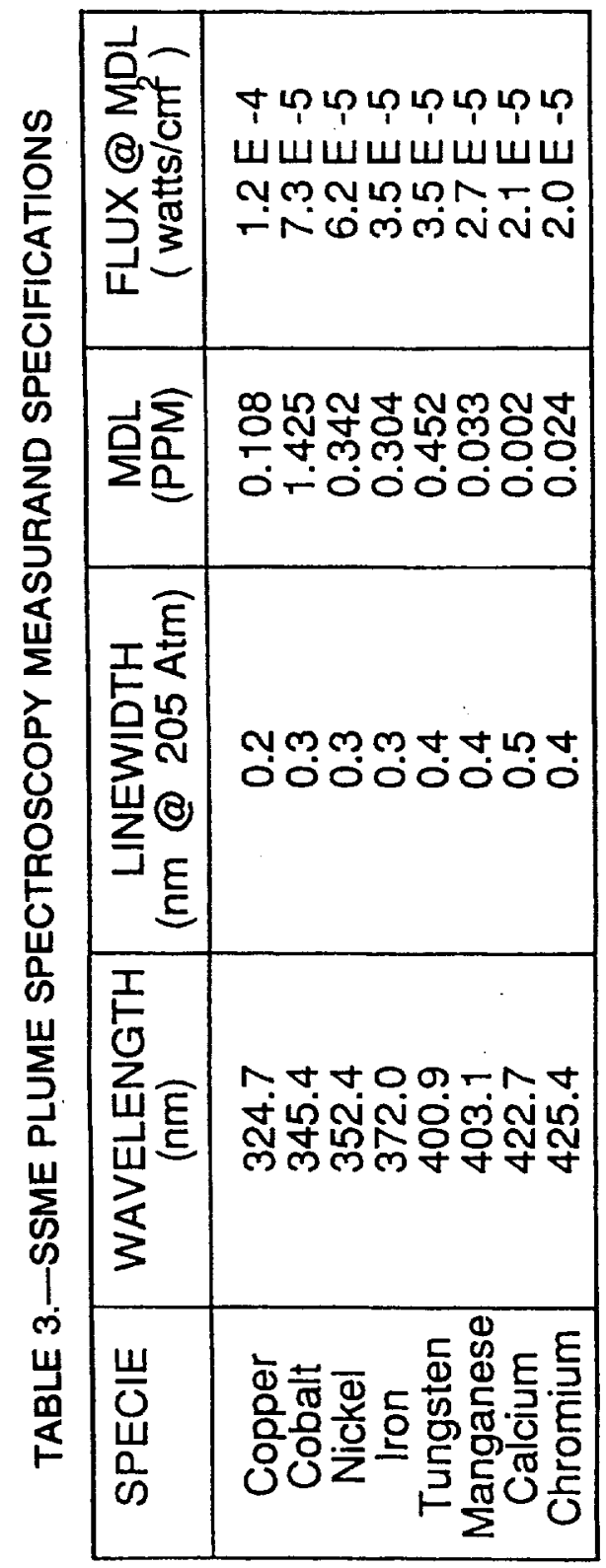




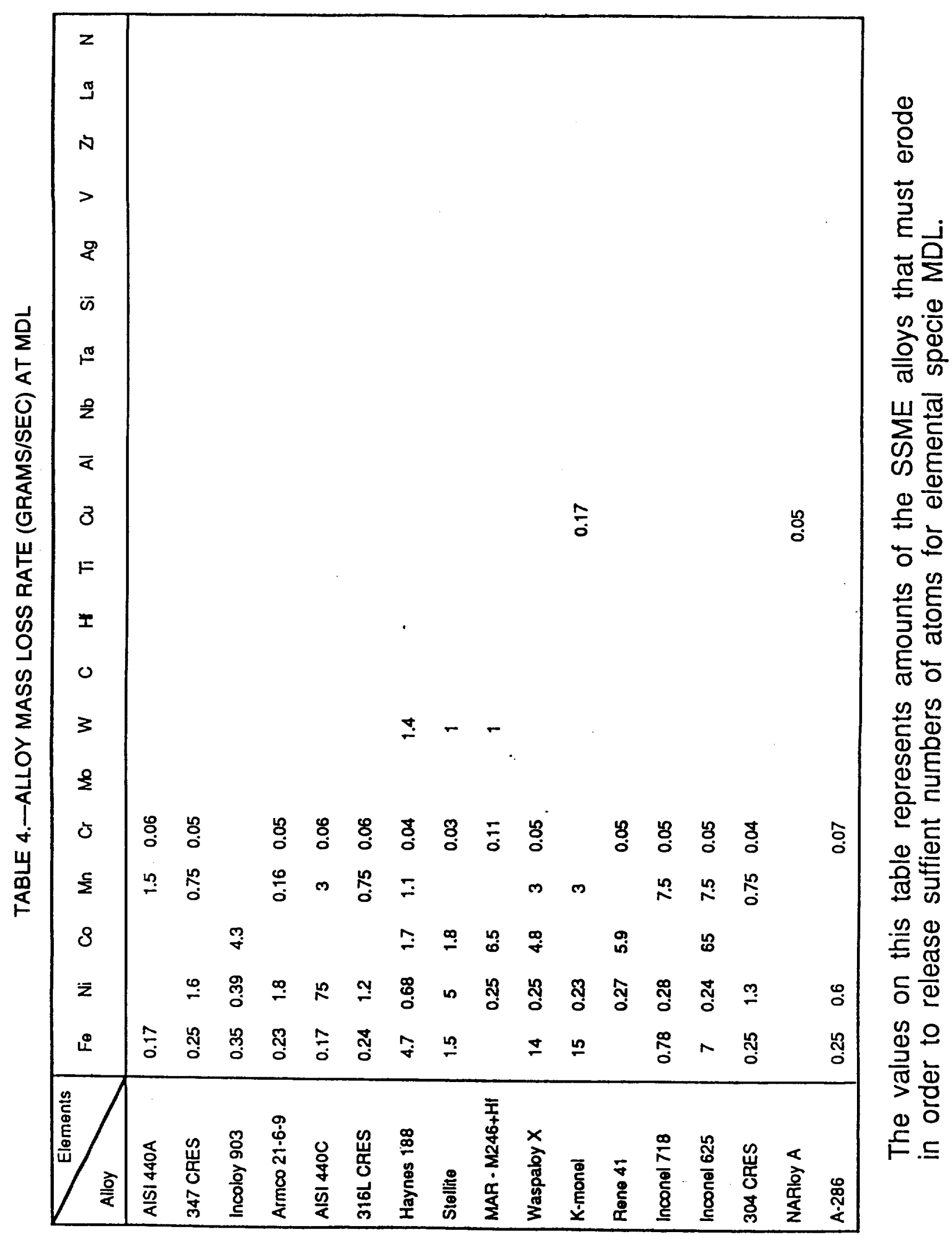




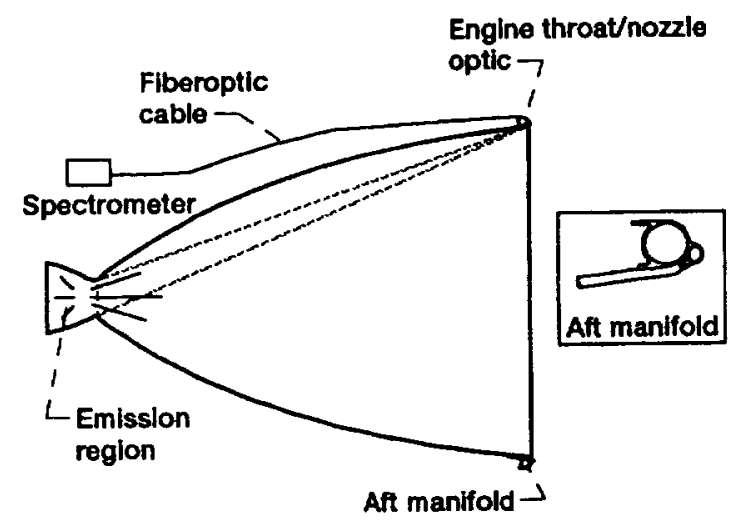

Figure 1. Schematic of optic system for flight

compatible plume spectroscopic capabilities.

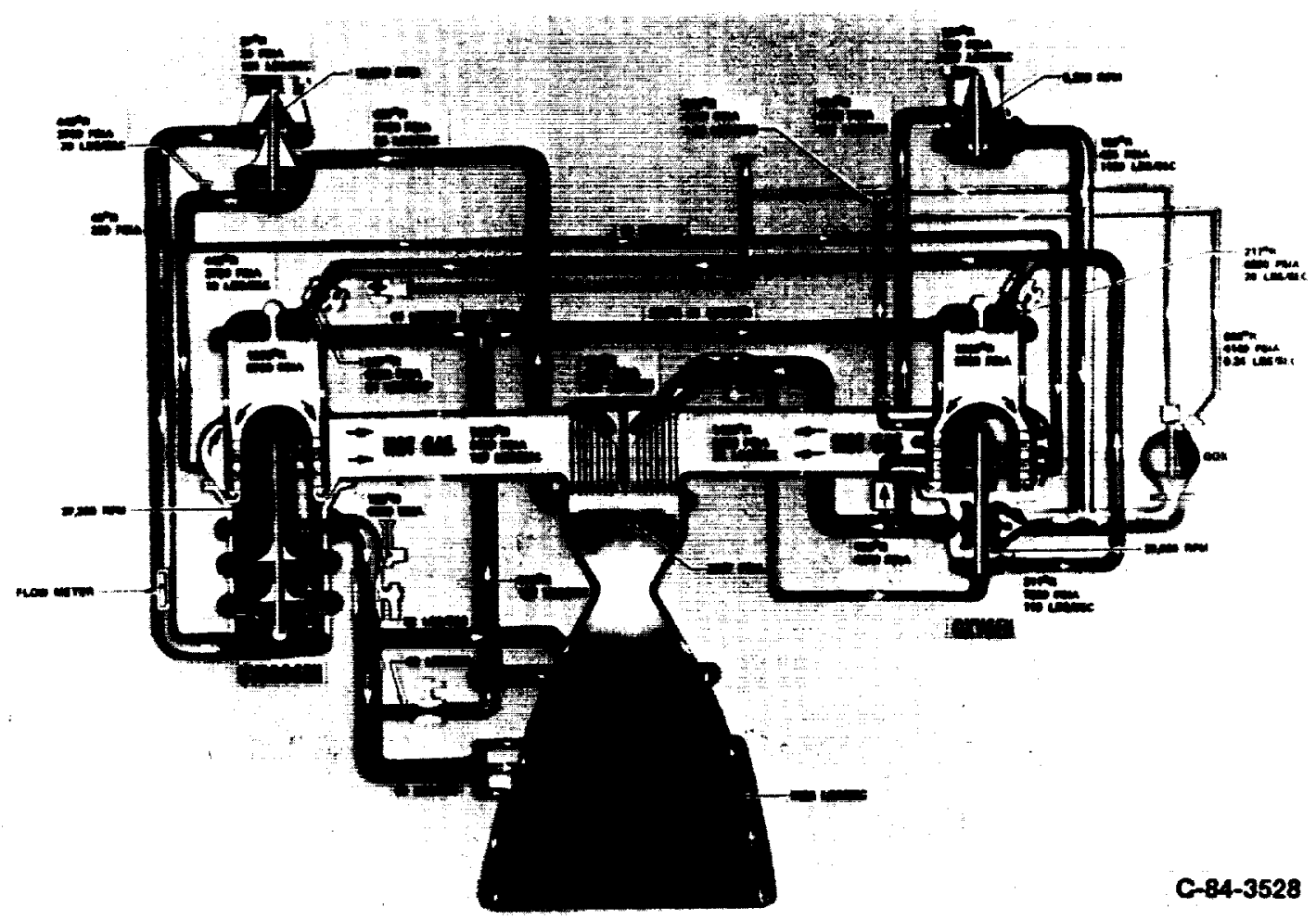

Figure 2.-SSME propellant flow paths. 


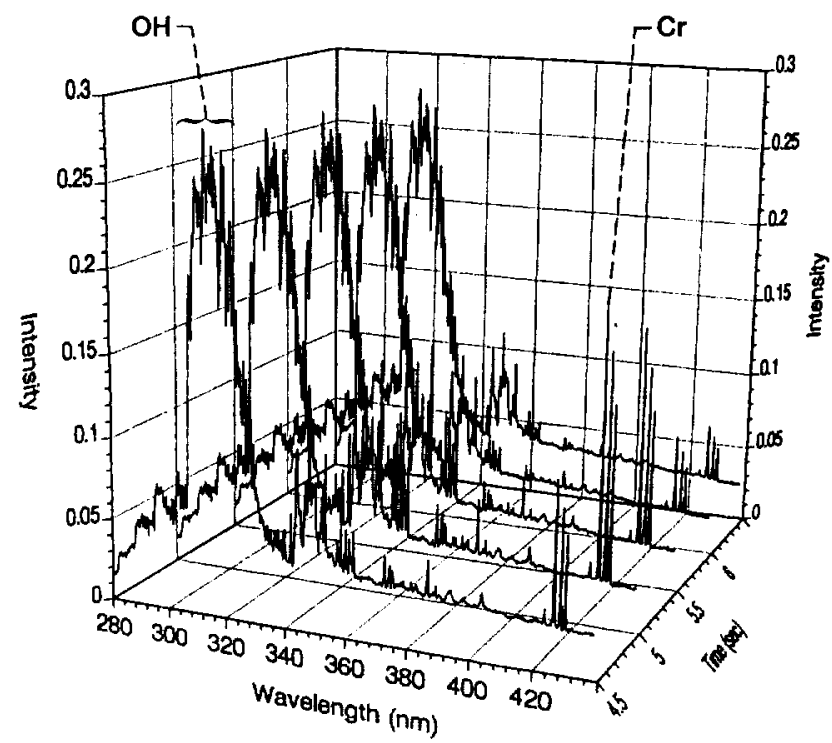

Figure 3.-Time series of emission spectra from TTBE firing number 024.
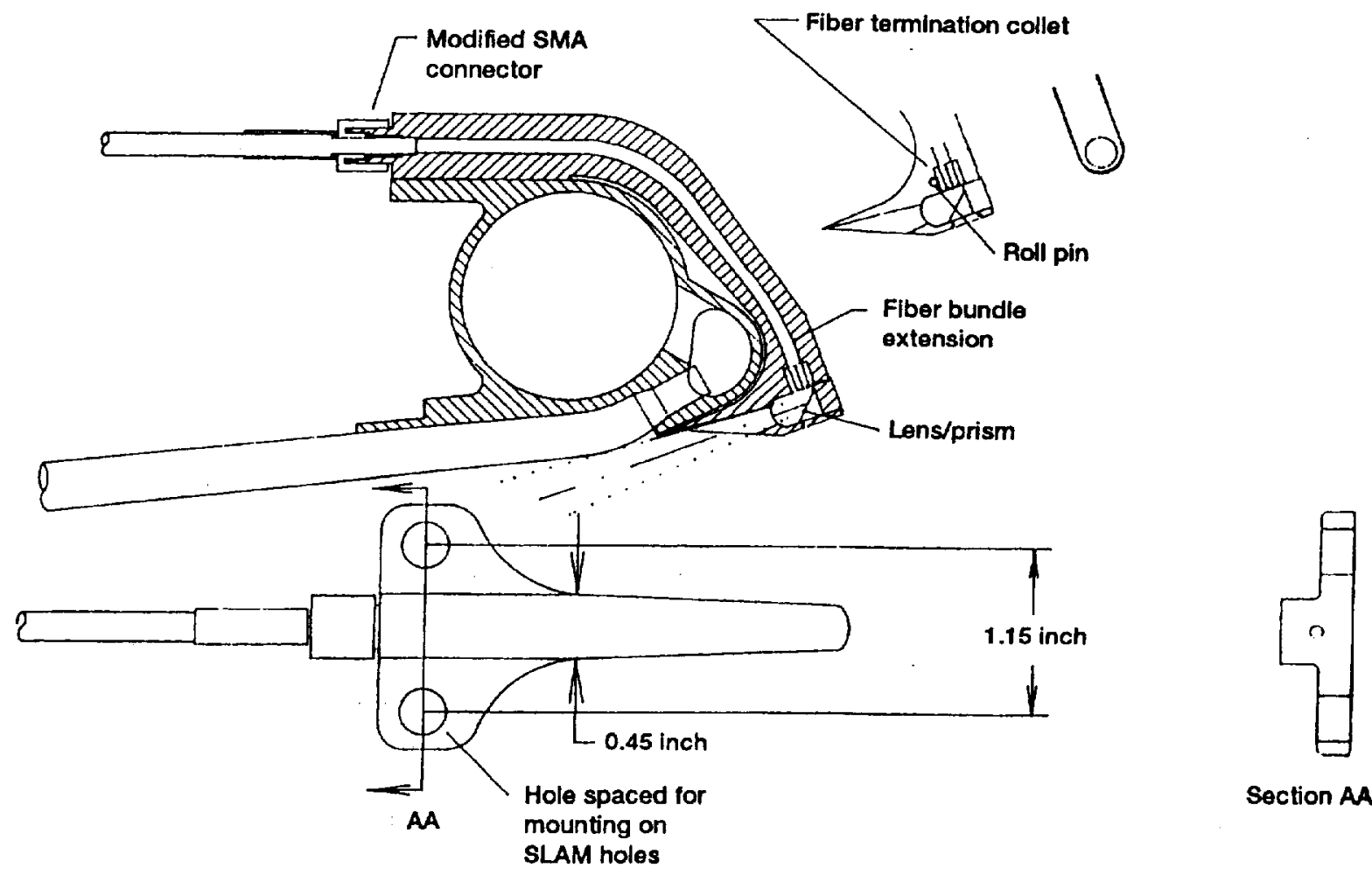

Section AA

Figure 4.-Schematic of nozzle mounted optic assembly. 

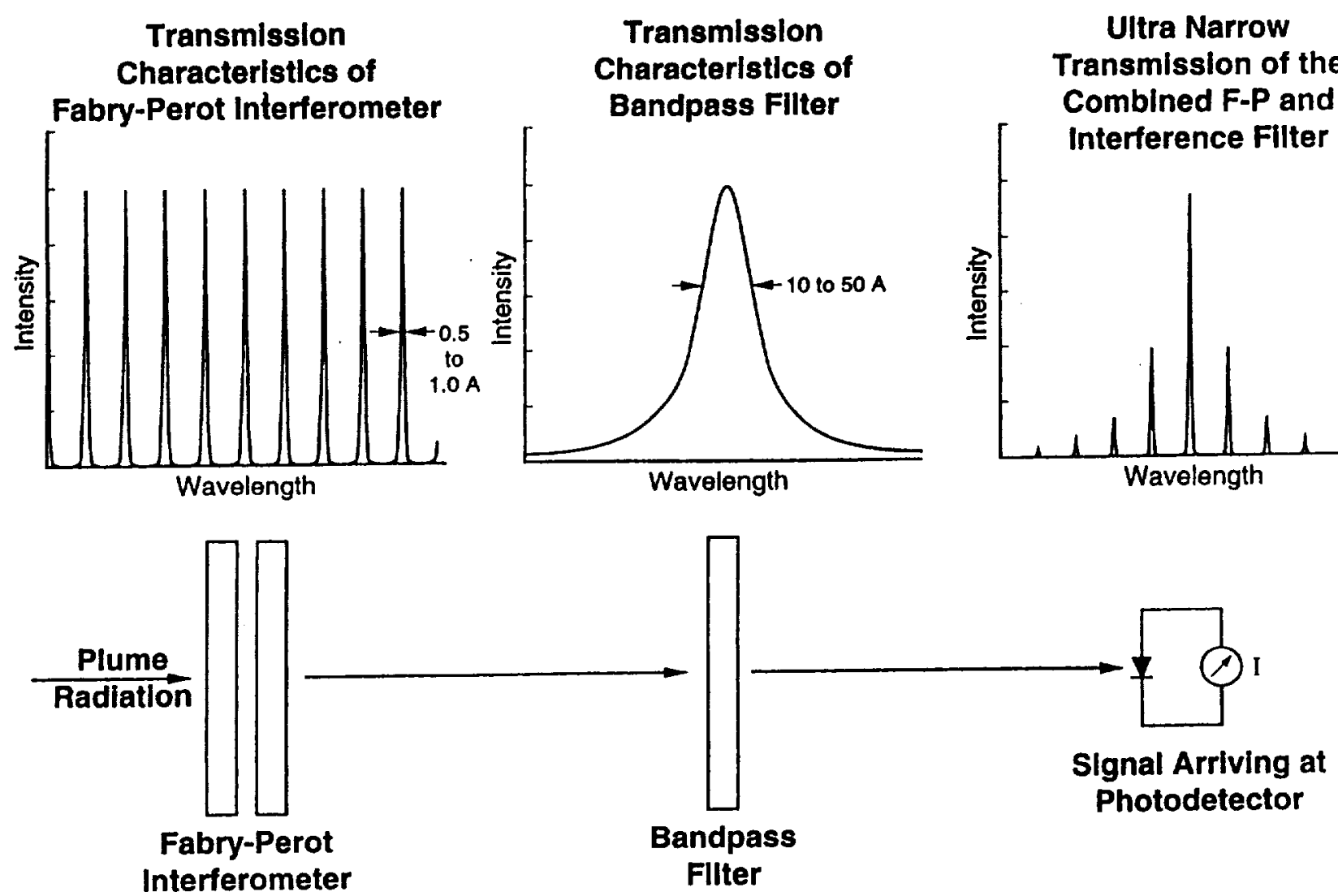

Figure 5.-FPI spectrometer filtering scheme.

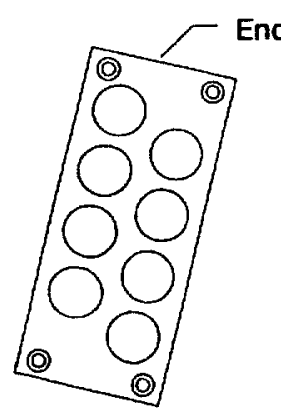

PMT socket retainer (plastic)
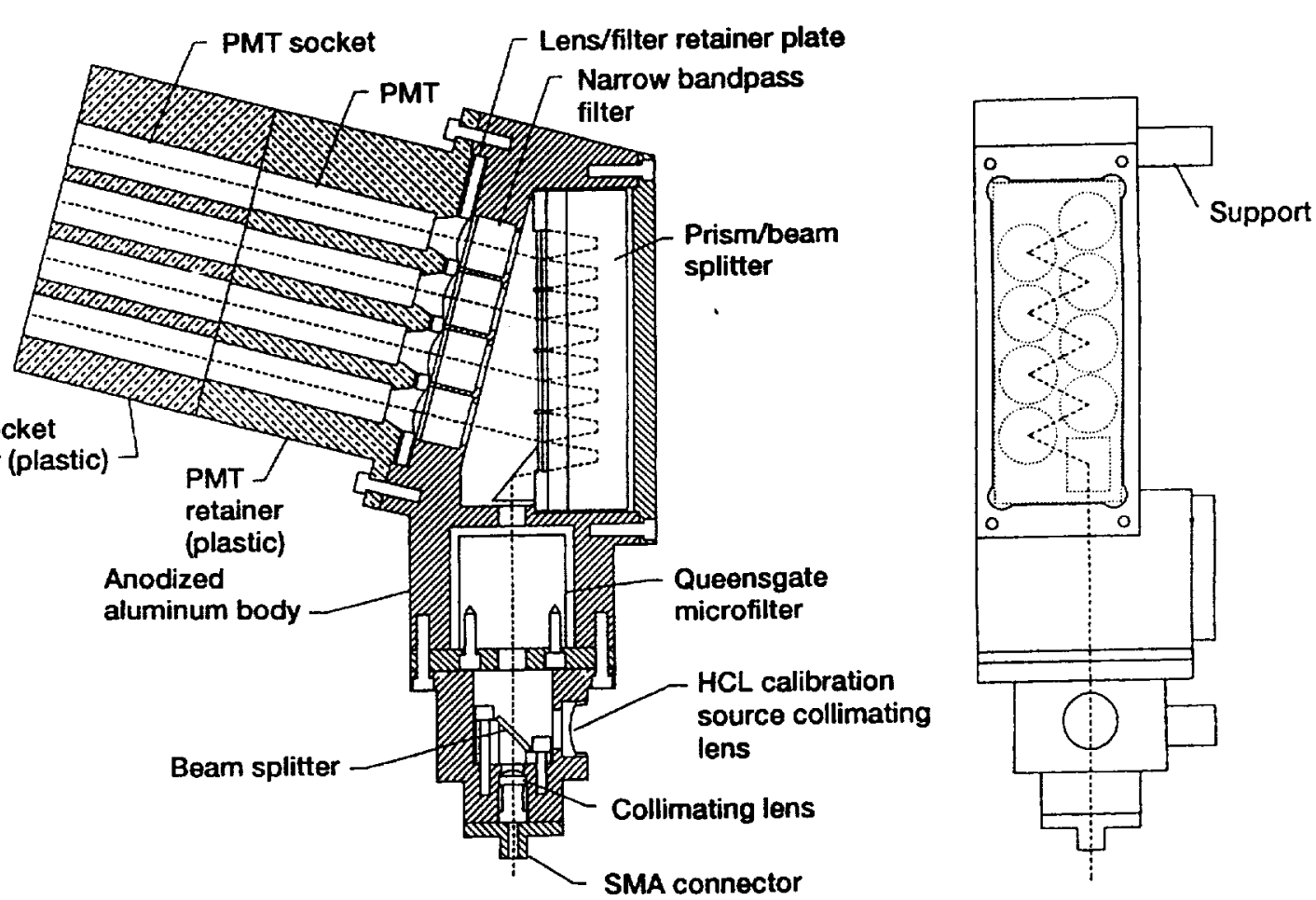

Figure 6.-FPI interferometeric spectrometer. 


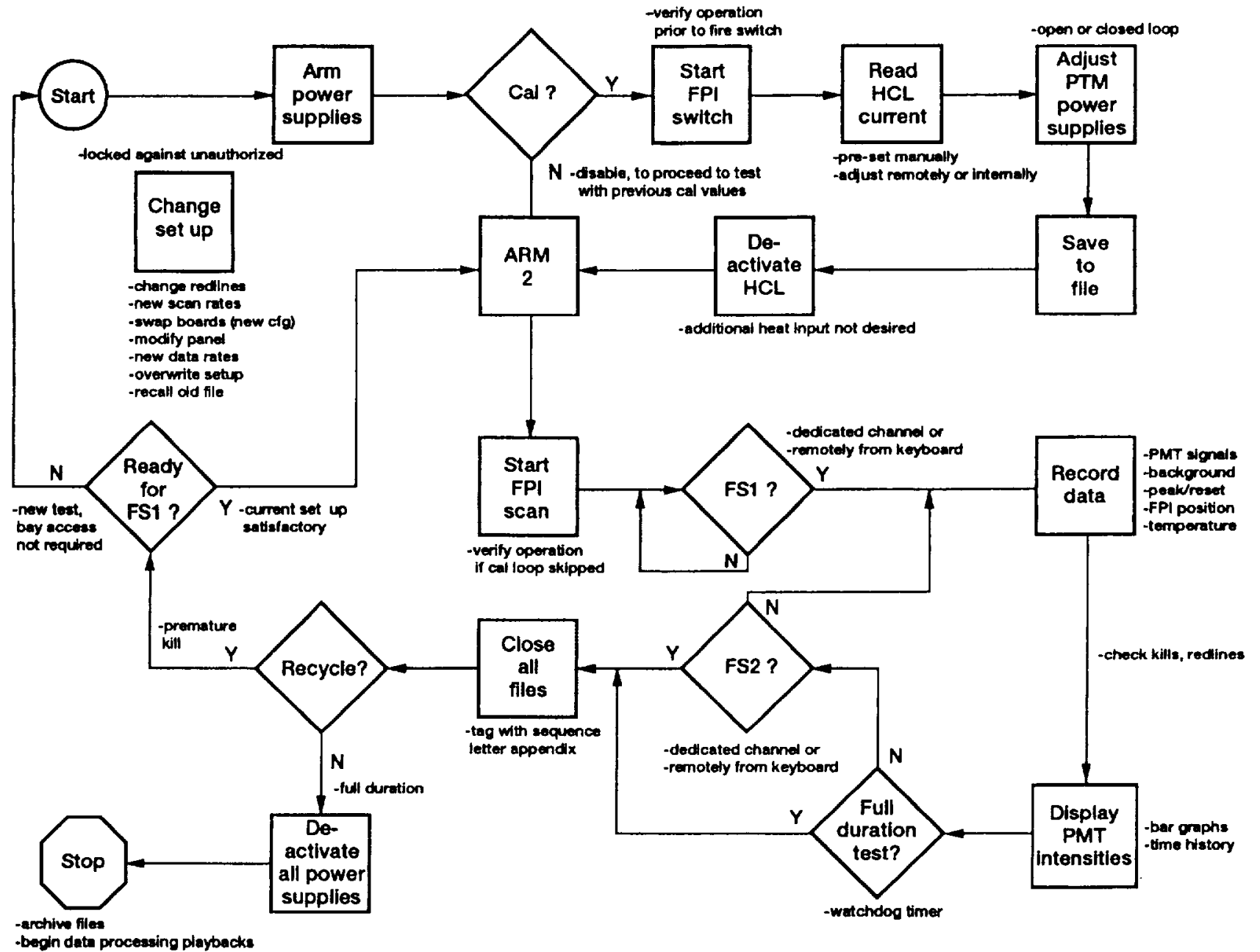

Figure 7.-Schematic of data acquisition and control logic for FPI spectrometer system.

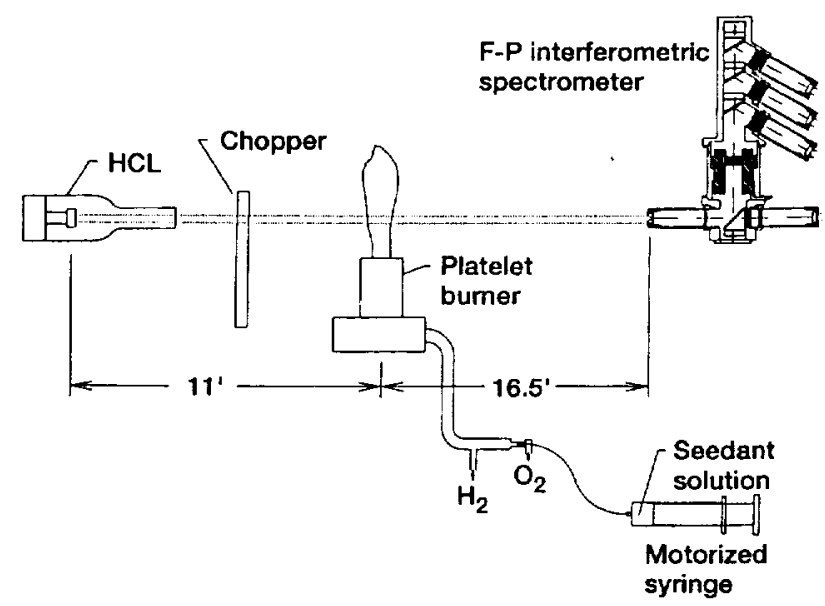

Figure 8.-Experimental set-up for testing spectrometer.

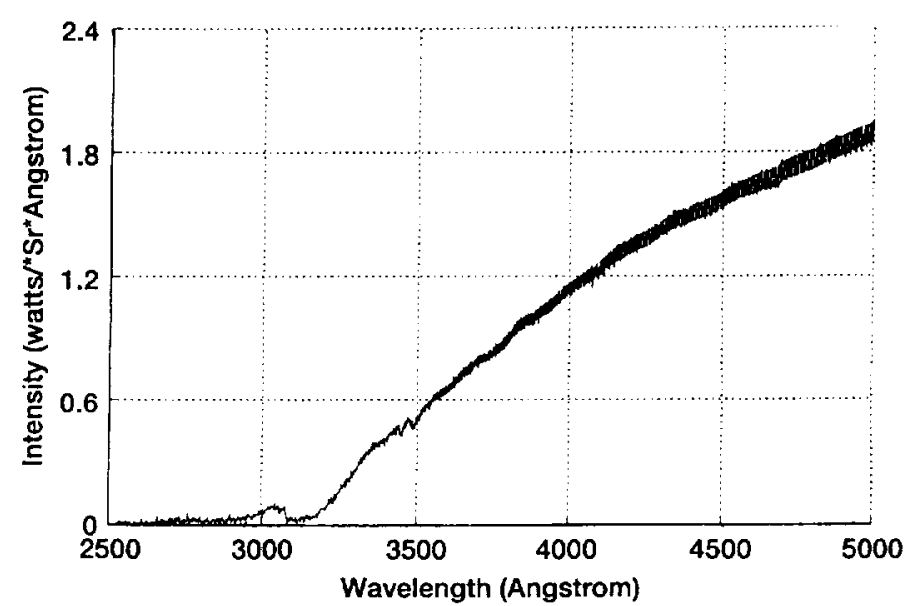

Figure 9.-Emission spectrum from chamber/throat of the SSME. 
Public reporting burden for this collection of information is estimated to average 1 hour per response, including the time for reviewing instructions, searching existing data sources, gathering and maintaining the data needed, and completing and reviewing the collection of information. Send comments regarding this burden estimate or any other aspect of this collection of intormation, including suggestions for reducing this burden, to Washington Headquarters Services, Directorate for information Operations and Reports, 1215 Jefferson Davis Highway, Suite 1204, Arlington. VA 22202-4302, and to the Office of Management and Budget, Paperwork Reduction Project (0704-018B). Washington, DC 20503.

\begin{tabular}{|l|c|c|}
\hline 1. AGENCY USE ONLY (Leave blank) & $\begin{array}{c}\text { 2. REPORT DATE } \\
\text { July } 1992\end{array}$ & $\begin{array}{l}\text { 3. REPORT TYPE AND DATES COVERED } \\
\text { Technical Memorandum }\end{array}$ \\
\hline
\end{tabular}

\section{TITLE AND SUBTITLE}

An Overview of In-Flight Plume Diagnostics for Rocket Engines

G.C. Madzsar, R.L. Bickford, and D.B. Duncan
WU $-590-21-41$

Pefforming organization REPORT NUMBER

$E-7130$

National Aeronautics and Space Administration

Lewis Rescarch Center

5. FUNDING NUMBERS

Cleveland, Ohio 44135-3191

10. SPONSORING/MONITORING AGENCY REPORT NUMBER

National Aeronautics and Space Administration

Washington, D.C. 20546-0001

NASA TM-105727

AIAA-92-3785

\section{SUPPLEMENTARY NOTES}

Prepared for the 28th Joint Propulsion Conference and Exhibit, cosponsored by AIAA, SAE, ASME, and ASEE, Nashville, Tennessee, July 6-8, 1992. G.C. Madzsar, NASA Lewis Research Center, Cleveland, Ohio, R.L. Bickford, Aerojet Propulsion Division, Sacramento, California, and D.B. Duncan, Duncan Technologies, Auburn, California. Responsible person, G.C. Madzsar, (216) 433-7434.

12a. DISTRIBUTION/AVAILABILITY STATEMENT

12b. DISTRIBUTION CODE

Unclassified - Unlimited

Subject Category 20

\section{ABSTRACT (Maximum 200 words)}

This paper presents an overview and progress report of the work performed or sponsored by the NASA Lewis Research Center (LeRC) toward the development of in-flight plume spectroscopy technology for health and performance monitoring of liquid propellant rocket engines. The primary objective of this effort is to develop technology that can be utilized on any flight engine. This technology will be validated by a hardware demonstration of a system capable of being retrofitted onto the Space Shuttle Main Engines for spectroscopic measurements during flight. The philosophy on system definition and status on the development of instrumentation, optics, and signal processing with respect to implementation on a flight engine are discussed in this paper.

14. SUBJECT TERMS

Spectroscopy; Plume; Emission; Radiation; Monitoring; Rocket engine

15. NUMBER OF PAGES 24

16. PRICE CODE

A03

\begin{tabular}{|c|c|}
\hline 17. SECURITY CLASSIFICATION & 18. SECURITY CLASSIFICATION \\
OF REPORT & OF THIS PAGE \\
Unclassified & Unclassified
\end{tabular}
19. SECURTY CLASSIFICATION OF ABSTRACT Unclassified 